\title{
Adsorption of Fluoride Ion onto Zirconyl-Impregnated Activated Carbon Prepared from Lapsi Seed Stone
}

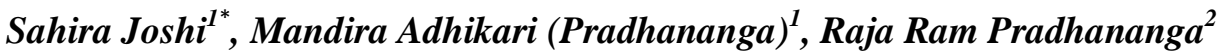 \\ ${ }^{1}$ Department of Engineering Science and Humanities, Institute of Engineering, Tribhuvan University, ${ }^{2}$ \\ Central Department of Chemistry, Tribhuvan University, Nepal. \\ Email: Sahira Joshi (sjoshi61@hotmail.com)
}

\begin{abstract}
The potentials of activated carbon derived from Lapsi (Choerospondias axillaries) seed stone after impregnation with zirconium for adsorptive removal of fluoride is presented. Activated carbons from Lapsi seed stone were prepared by three different techniques. Firstly by directly burning in limited supply of air, secondly by treating with a mixture of conc. $\mathrm{H}_{2} \mathrm{SO}_{4}$ and $\mathrm{HNO}_{3}$ (in the ratio of 1:1 by weight) and thirdly by activation with zinc chloride (in the ratio of 1:1 by weight) followed by carbonization at $400^{\circ} \mathrm{C}$ and $500^{\circ} \mathrm{C}$ under nitrogen atmosphere. Thus prepared carbons were impregnated with zirconyl oxychloride and effects of $\mathrm{pH}$, adsorbent dose, and contact time and adsorbate concentration for the removal of fluoride were evaluated by batch mode. The optimum $\mathrm{pH}$ for adsorption of fluoride was observed at pH 3-4, and a minimum contact time for the maximum defluoridation was found to be 180 min. The Langmuir and Freundlich isotherms were used to describe adsorption equilibrium. Zirconium impregnation increased the fluoride adsorption capacity of carbon to considerable extent. Among carbon prepared by three different techniques, the carbon prepared from zinc chloride activation followed by carbonization showed relatively higher fluoride adsorption capacity. From the experiment it is concluded that activated carbon prepared from Lapsi seed is an efficient, low-cost alternative to commercial activated carbon for defluoridation of water.
\end{abstract}

Keywords: Adsorption, zirconium impregnated, Lapsi seed stone activated carbon, fluoride, adsorption Isotherms

\section{Introduction}

Fluoride $\left(\mathrm{F}^{-}\right)$contamination in groundwater has been recognized as one of the serious problems worldwide ${ }^{1}$. Fluoride is classified as one of the contaminants of water for human consumption by the World Health Organization in addition to arsenic, which causes large-scale health problems ${ }^{2}$. Fluoride is widely distributed in the geological environment and generally released into the groundwater by slow dissolution of fluorine-containing rocks such as granite, basalt, syenite, and shale et. al. ${ }^{3}$ Besides the natural geological sources, various industries are also contributing for fluoride enrichment in groundwater ${ }^{4}$. The industries which discharge wastewater containing high fluoride concentrations include glass and ceramic production, semiconductor manufacturing, electroplating, coal fired power stations, beryllium extraction plants, brick and iron works, and aluminum smelters ${ }^{5}$. The effluents of these industries have higher fluoride concentrations than natural waters, ranging from ten to thousands of $\mathrm{mg} / \mathrm{L}^{6}$. Elevated fluoride concentrations in the groundwater occur in various parts of the world ${ }^{7}$.

\section{${ }^{*}$ Corresponding author}


Depending on the concentration and the duration of continuous uptake, the impact of fluoride in drinking water can be beneficial or detrimental to mankind. Fluoride in drinking water has a profound effect on teeth and bones. Up to a small level $(1-1.5 \mathrm{mg} / \mathrm{L})$ this strengthens the enamel of teeth. Concentrations in the range of $1.5-4 \mathrm{mg} / \mathrm{L}$ result in dental fluorosis and with prolonged exposure and higher fluoride concentrations $(4-10 \mathrm{mg} / \mathrm{L}$ ) progresses to skeletal fluorosis. The distribution and health effects of fluoride have recently been reviewed ${ }^{8}$. Hence, the WHO provisional guideline value of $1.5 \mathrm{ppm}$ $(1.5 \mathrm{mg} / \mathrm{l})$ for fluoride has been adopted ${ }^{2}$, and the same value has been adopted in Nepal as drinking water standard. However it is estimated that more than 200 million people are using drinking water containing more than $1.5 \mathrm{mg} / \mathrm{L}$ of fluoride ${ }^{2}$ concentrations.

In the groundwater fluoride concentrations of more than $30 \mathrm{mg} / \mathrm{L}$ was observed in different parts of the world, notably the arid parts of China, India, Sri Lanka, West Africa (Ghana, Ivory Coast, Senegal), North Africa (Libya, Sudan, Tunisia), South Africa, the East African Rift Valley (Kenya, Uganda, Tanzania, Ethiopia, Rwanda), Northern Mexico, and Central Argentina ${ }^{9}$. About 260 million people in the world, mostly in India and China are facing the problem of excess fluoride in drinking water ${ }^{2}$. In Nepal, practically, only little works exists on ground water contamination by toxic elements other than arsenic. Limited surveys were conducted in the low land of Terai region. It has been reported that, the ground water in Kailali district was contaminated with arsenic, iron together with fluoride, lead, molybdenum, boron and zinc $^{10}$. Since, groundwater is a significant source for drinking water in Nepal ${ }^{11}$, and any contamination of groundwater could lead to severe consequences.

To assess this fluoride risk, quantification of fluoride ions in ground water must be performed and adaptation of effective defloridation methodology. Most prevalent de-fluoridation technologies involve adsorption $^{4}$, ion exchange ${ }^{12}$, precipitation ${ }^{13}$, Donnan dialysis ${ }^{14}$, electrodialysis ${ }^{15}$, reverse osmosis ${ }^{16}$ nanofiltration ${ }^{17}$ and ultra-filtration ${ }^{18}$. Owing to various drawbacks associated with conventional defluoridation techniques, adsorption-based fluoride removal is emerging as a feasible option. Furthermore, the technique is robust, environmentally benign, and simple ${ }^{19}$. This technique offers satisfactory results especially with surface modified and/or mineral-based adsorbents. Various types of adsorbents namely alumina ${ }^{20}$, activated carbon ${ }^{21}$, bone charcoal ${ }^{22}$ synthetic ion exchangers ${ }^{23}$ and other materials ${ }^{24,25}$ have been used with different degrees of success. Among these adsorbents, activated carbons and modified activated carbon have great potential due to their strong affinity for fluoride ${ }^{26}$.

Recently, considerable work has been conducted in developing new adsorbents impregnated with metal ions (surface modified) for the adsorptive removal of fluoride. Activated carbon when impregnated with metal ions has their fluoride adsorption capacity multiplied by 3 to 5 times compared to plain activated carbon. ${ }^{27}$. Because of the high electro-negativity and small ionic size of the fluoride ion, it has a strong affinity towards multivalent metal ions including $\mathrm{Al}$ (III), $\mathrm{Fe}$ (III) and $\mathrm{Zr}$ (IV) ${ }^{28}$. The adsorbents that use rare earth elements are attracting more and more attention because of their selective affinity to fluoride, high adsorption capacity, little induced pollution, and easy operation ${ }^{28}$. Zirconium and its metal complexes have been conventionally used for the colorimetric determination of fluoride due to the high affinity of zirconium for fluoride ion ${ }^{26}$.The high charge density of the fluoride ion enables it to form stable fluoro-complexes with tetravalent metal ions like zirconium (IV $)^{29}$. Furthermore, a detailed literature survey has revealed that, zirconium impregnated activated carbon have already been used for treating phosphate, arsenic, selenium, mercury and chromium (VI) from water samples. The presence of these co-ions (anions and cations) interfere with fluoride ion uptake by principle of competition for the adsorption sites on the zirconium impregnated activated carbon and fluoride ion decreased the co-adsorption of As (V), Se (IV), and Hg (II) ${ }^{30}$. Similarly, experimental results has also shown that, fluoride adsorption capacity of zirconium impregnated coconut shell carbon is 25 to 30 times that of plain activated carbon. ${ }^{31}$. It shows that zirconium has high affinity towards fluoride ion ${ }^{32}$. In addition, study on fluoride adsorption using zirconium impregnated coconut shell fiber carbon $^{33}$. Zirconium impregnated ground nut shell carbon and zirconium impregnated cashew nut shell 
carbon $^{34}$ and zirconium impregnated Collagen fiber ${ }^{35}$ also have shown promising results in fluoride adsorption.

However, widespread use of commercial activated carbon is sometimes restricted due to its higher costs. Attempts have been made to develop inexpensive adsorbents utilizing numerous agro-industrial and municipal waste materials. Hence, biomass mainly derived from agricultural and industrial waste is a preferable option for low cost activated carbon precursors. These precursors include coconut shell and wood, olive stones, sugarcane bagasse, pecan shells, palm seeds, apple pulp, and rubber seeds etc. ${ }^{36}$. Use of these waste materials as low-cost adsorbents is attractive due to their contribution in the reduction of costs for waste disposal, therefore contributing to environmental protection. Lapsi (Choerospondias Axillaries) is one of the popular fruits in Nepal whose fleshy part is used to make candy, pickles etc. Its seed stones are used only as fuel in brick kilns. ${ }^{37}$. Recently Lapsi fruit stone had been used as a precursor for preparation of activated charcoal for adsorption arsenic and heavy metals ${ }^{38,39}$. The present study deals with the preparation of activated carbon from Lapsi seed stone as an adsorbent for the removal of Fluoride from water.

\section{Experimental method}

Lapsi seed stones, as waste-products of the Lapsi fruit, were used to prepare fluoride adsorbent in this study. For the better research output, the different methods were applied to prepare adsorbent of Lapsi seed stone. The adsorbent was then characterized and used as adsorbent for fluoride ion. The method used in this study can be explained as follows.

\section{Preparation of activated carbon from Lapsi seed stones as an adsorbent}

The Lapsi seed stone were washed several times with distilled water and dried in sunlight for a week. Then it was dried at $105^{\circ} \mathrm{C}$. After drying, it was crushed in a grinder to obtain raw powdered of Lapsi seed stone. The dried powdered Lapsi seed stones were processed to obtained different types of activated carbon as described below.

$\boldsymbol{I}^{\text {st }}$ type: By burning directly in air: The dried Lapsi seed stones were burnt in air till blue flame ceases. The charcoal obtained was cooled and grounded in a mortar and sieved for 40 mesh.

$2^{\text {nd }}$ type: By treating with conc. $\mathrm{H}_{2} \mathrm{SO}_{4}$ : $100 \mathrm{gm}$ of crushed powdered was taken and 50 gm of sulfuric acid was added gradually. The mixture was subjected in an air oven at $110^{\circ} \mathrm{C}$ for 24 hours. The carbonized material was washed with distilled water to remove excess sulfuric acid and dried at $110^{\circ} \mathrm{C}$ for overnight. The sample was then ground in a mortar and sieved using 40 mesh.

$3^{\text {rd }}$ type: By treating with a mixture of conc. $\mathrm{H}_{2} \mathrm{SO}_{4}$ and $\mathrm{HNO}_{3}$ : $50 \mathrm{gm}$ of sulfuric acid was gradually added to $100 \mathrm{gm}$ of crushed powdered and cooled. $30 \mathrm{gm}$ of nitric acid was then added slowly with continuous stirring. The mixture was subjected in an air oven at $100{ }^{\circ} \mathrm{C}$ for 24 hours. The carbonized material was washed with distilled water to remove excess acid and dried at $85^{\circ} \mathrm{C}$ for overnight. The sample was then ground in a mortar and sieved using 40 mesh.

$4^{\text {rth }}$ type: By activation with zinc chloride followed by carbonization: $20 \mathrm{gm}$ of crushed powdered was mixed with $\mathrm{ZnCl}_{2}$ in the ratio of $1: 1$ by weight. Then $50 \mathrm{ml}$ distilled water was added to the mixture. The impregnation process was performed by shaken in magnetic stirrer at temperature about $70^{\circ} \mathrm{C}$ until the excess water had evaporated. The impregnated sample was dried in an oven at $110{ }^{\circ} \mathrm{C}$ overnight. The sample was placed inside a quartz tube and inserted horizontally into the middle of a tubular electric furnace. The carbonization and activation were carried out at $400{ }^{\circ} \mathrm{C}$ under $\mathrm{N}_{2}$ gas flow for 3 hours. The resulting activated carbon was washed with $1 \mathrm{M} \mathrm{HCl}$ followed by distilled water until traces of chloride ions were no longer detected. The sample was then dried at $110^{\circ} \mathrm{C}$ for overnight and stored in desiccator. 


\section{Metal Impregnation}

Among the different carbons prepared, the activated carbon prepared from zinc chloride activation followed by carbonization has shown slightly higher iodine number. Hence this activated carbon was taken for metal impregnation. $\mathrm{pH}$ and iodine Numbers of different types of Carbons are listed in Table 1.Activated carbon obtained from section 2.1 was immersed in $1 \%$ solution of sodium carbonate $\left(\mathrm{Na}_{2} \mathrm{CO}_{3} 10 \mathrm{H}_{2} \mathrm{O}\right)$ solution then washed with distilled water to remove excess alkali. Zirconium metal impregnation was carried out by mixing Lapsi Seeds Activated Carbon (LSAC) with 5\% $\mathrm{ZrOCl}_{2} 8 \mathrm{H}_{2} \mathrm{O}$ solution in the ratio of $1: 2$ by weight. The mixture was stirred for 3 days at room temperature $(298 \mathrm{~K})$ then filtered. The zirconium concentration in the effluent was determined using ammonia. Then Zirconium Impregnated Lapsi Seed Stone Carbon (ZILSSAC) was dried in an oven at $383 \mathrm{~K}$ and subsequently used for defluoridation studies.

\section{Characterization of activated carbon}

The characterization of the active carbons requires information on properties of the materials. Activated carbons from section 2.1 were characterized for $\mathrm{pH}$, moisture content, Ash content [in accordance with American Standard of Testing Material, ASTM D3838-80 (pH) 1999ASTM D3173 (moisture) and ASTM D3174 (ash) $]^{41}$. Quantification of Oxygen containing functional groups present on the activated carbons prepared was determined by Boehm titration method ${ }^{43}$. Iodine number of the carbons was determined to get the information about the surface area (ASTM D4607 - 94) ${ }^{43}$

\section{Adsorption studies}

A fluoride ion stock solution of $1000 \mathrm{mg} / \mathrm{L}$ was prepared by dissolving $221 \mathrm{mg}$ of anhydrous sodium fluoride in $100 \mathrm{~mL}$ distilled water in volumetric flask. Standard solutions of fluoride ion were prepared by subsequent dilution of the fluoride stock solution. Solutions of $0.1 \mathrm{M} \mathrm{NaOH}$ and $0.1 \mathrm{HCl}$ were used for $\mathrm{pH}$ adjustment.

The fluoride adsorption capacity of adsorbent (activated Carbon) was investigated using batch experiments. The defluoridation experiment was performed by mixing certain amount of adsorbent with sodium fluoride solution containing various concentration of fluoride concentration. The mixture was agitated in a thermostatic shaker at a speed of $200 \mathrm{rpm}$ at room temperature for a prescribed time to attain the equilibrium. At the end of each equilibrium time, the solution were filtered and fluoride ion concentration in water samples was measured by SPANDS method using UV/VIS spectrophotometer as per the procedure of standard methods of examination of water and waste water ${ }^{40}$. The defluoridation studies were conducted for the optimization of various experimental conditions like contact time, dose, $\mathrm{pH}$.

Fluoride uptake $\left(\mathrm{q}_{\mathrm{e}}\right)$ was determined from eq. (1)

$$
\mathrm{q}_{\mathrm{e}}=(\mathrm{Co}-\mathrm{Ce}) \frac{V}{\mathrm{~m}}
$$

Where, $\mathrm{C}_{\mathrm{o}}$ is the initial concentration $(\mathrm{mg} / \mathrm{L}), \mathrm{C}_{\mathrm{e}}$ the concentration at equilibrium $(\mathrm{gm} / \mathrm{L}), \mathrm{q}_{\mathrm{e}}$ the amount adsorbed at equilibrium ( $\mathrm{mg} / \mathrm{g}$ ), $m$ the adsorbent mass $(\mathrm{gm})$ and $V$ is the solution volume (L).

\section{Results and Discussion}

\section{Determination of $\mathrm{pH}$ and Iodine Number}

Four types of activated carbon prepared as described in section 2.1 were subjected for the determination of $\mathrm{pH}$ and iodine number. For the $\mathrm{pH}$ determination, $1.0 \mathrm{gm}$ of activated carbon was taken in a beaker and $100 \mathrm{ml}$ of distilled water was added then stirred for one hour. Samples were allowed to 
stabilize and then $\mathrm{pH}$ was measured using a $\mathrm{pH}$ meter (Corning $250 \mathrm{pH} /$ ion anlyzer). For determination of iodine number, $10 \mathrm{ml}$ of $5 \%$ by weight of $\mathrm{HCl}$ was added to $1 \mathrm{~g}$ of activated carbon and was allowed to boil. The solution was cooled to room temperature then $100 \mathrm{ml}$ of $0.1 \mathrm{~N}$ iodine solution was added. The content was shaken vigorously and filtered. $25 \mathrm{ml}$ of the filtrate was titrated with $0.1 \mathrm{~N}$ sodium thiosulphate in the presence of starch as indicator. $\mathrm{pH}$ and iodine numbers of four types of activated carbons are listed in Table 1 . It has shown that iodine number of $4^{\text {th }}$ type activated carbon is higher than other types of activated carbon which is attributed to the complete carbonization of Lapsi seed stone powder. The higher value of iodine number indicates that the carbon is highly porous with better effective surface area. Therefore, $4^{\text {th }}$ type activated carbon was selected to prepare an adsorbent in this study.

Table 1: $p H$ and Iodine numbers of different types of Activated carbons

\begin{tabular}{|l|c|c|}
\hline \multicolumn{1}{|c|}{ Types of Activated Carbon(AC) } & pH & $\begin{array}{c}\text { Iodine number } \\
(\mathbf{m g} / \mathbf{g m})\end{array}$ \\
\hline $1^{\text {st }}$ type $($ Air burnt $\mathrm{AC})$ & 5.9 & 259 \\
\hline $2^{\text {nd }}$ type $\left(\mathrm{H}_{2} \mathrm{So}_{4}\right.$ activated $\left.\mathrm{AC}\right)$ & 5.5 & 377 \\
\hline $3^{\text {rd }}$ type $\left(\mathrm{H}_{2} \mathrm{So}_{4}\right.$ and $\mathrm{HNo}_{3}$ activated $\left.\mathrm{AC}\right)$ & 5.4 & 398 \\
\hline $4^{\text {th }}$ type $\left(\mathrm{Zncl}_{2}\right.$ impregnated Carbon) & 6.8 & 745 \\
\hline
\end{tabular}

\section{The physiochemical properties of the adsorbent}

The $4^{\text {th }}$ type activated carbon was characterized in more detail by measuring moisture content and ash content. The values are tabulate in Table 2. Moisture content of the samples was measured by thermal drying method. $1.0 \mathrm{~g}$ of the dried activated carbons were taken in a crucible and dried in an oven at $110^{\circ} \mathrm{C}$ for $4 \mathrm{hrs}$ for constant weight and moisture content was calculated.

Ash content shows the amount of inorganic substituent present in the carbon. High ash content is undesirable for activated carbon since it reduces the mechanical strength of carbon and affects adsorptive capacity. A crucible was pre-heated in a muffler furnace to about $500^{\circ} \mathrm{C}$, cooled in a desiccator and weighed. $1.0 \mathrm{~g}$ of activated carbon samples were transferred into the crucibles and reweighed. The crucibles containing the samples were heated to $500^{\circ} \mathrm{C}$ in a muffler furnace. It was removed and allowed to cool in a desiccator to room temperature and reweighed again. The ash content was calculated using the equation 2. Table 2 shows that ash content and moisture content of $4^{\text {th }}$ type activated carbon are low which indicates that activated carbon is suitable for adsorption process.

$$
\operatorname{Ash}(\%)=\{\text { wt. of ash }(\mathrm{gm}) / \text { dry wt.of activated charcoal }(\mathrm{gm})\} \times 100
$$

Table 2: The physiochemical properties of the adsorbent

\begin{tabular}{|c|c|}
\hline Parameters & $4^{\text {th }}$ type activate Carbon \\
\hline Moisture Content & $0.24 \%$ \\
\hline Ash Content & $3.51 \%$ \\
\hline
\end{tabular}




\section{Determination of oxygen containing functional groups}

Acidic functional groups such as carboxyl, phenolic and others on the surface of carbon present in the $4^{\text {th }}$ type activated carbon were determined by Boehm titration method. For the process, $0.2 \mathrm{gm}$ of samples in $50 \mathrm{~mL}$ of $0.05 \mathrm{M} \mathrm{NaOH}, \mathrm{Na}_{2} \mathrm{CO}_{3}$ and $\mathrm{NaHCO}_{3}$ was shaken separately for $24 \mathrm{hr}$ and filtered through Whatman No 40 filter paper. After filtration, $5 \mathrm{~mL}$ of each solution were titrated with $0.05 \mathrm{M}$ $\mathrm{HCl}$ solution using phenopthalein as indicator. The number and type of acidic sites were calculated by considering that $\mathrm{NaOH}$ neutralizes carboxyl, lactonic and phenolic groups, $\mathrm{Na}_{2} \mathrm{CO}_{3}$ neutralizes carboxylic and lactonic groups and that $\mathrm{NaHCO}_{3}$ neutralizes only carboxylic groups. Table 3 shows the presence of acid functional groups such as carboxyl, phenolic and lactonic in milliequivalent $/ \mathrm{gm} .{ }^{43}$ It is considered that the hydrogen ions present in the functional groups may replaced by zirconyl ion on metal impregnation of the activated carbon.

Table 3: The acidic surface functional groups in the $\mathrm{ZnCl}_{2}$ impregnated activated carbon

\begin{tabular}{|c|c|c|c|}
\hline \multirow{2}{*}{ Adsorbent } & \multicolumn{3}{|c|}{ Functional groups in millequivalent } \\
& \multicolumn{3}{|c|}{ per gram (meq/g) } \\
\cline { 2 - 4 } & Carboxyl & Phenol & Lactones \\
\hline $4^{\text {th }}$ type activated carbon & 0.104 & 0.213 & 0.326 \\
\hline
\end{tabular}

\section{Effect of contact time}

Contact time was carried out by mixing $0.2 \mathrm{gm}$ of adsorbent with $100 \mathrm{ml}$ of sodium fluoride containing $10 \mathrm{mg} / \mathrm{L}$ as initial fluoride concentration. The mixture was agitated in a thermostatic shaker at a speed of $200 \mathrm{rpm}$ at room temperature. Figure 1 illustrates the amount of fluoride adsorbed per $\mathrm{gm}$ of adsorbent (Zirconium Impregnated Lapsi Seed Stone Activated Carbon, ZILSSAC) as a function of contact time in the range of $25-400 \mathrm{~min}$ at room temperature. The values are increasing linearly up to $150 \mathrm{~min}$ and thereafter it remained almost constant indicating the attainment of adsorption equilibrium. Therefore $150 \mathrm{~min}$ was fixed as minimum contact time for the maximum defluoridation of the sorbent. The zirconium impregnated Lapsi seed stone carbon recorded a maximum amount of fluoride adsorbed per gm of adsorbent $\left(\mathrm{q}_{\mathrm{e}}\right)$ was found to be $1.6 \mathrm{mg} / \mathrm{gm}$. The sudden rise in removal of fluoride indicates that the adsorption of fluoride probably takes place due to the diffusion taking place into the pores on the surface of the adsorbent. The removal of fluoride ions from water, increases with increase in agitation time to some extent, after which, increase in agitation time does not increase the fluoride uptake due to deposition of fluoride ions on the available adsorption sites on ZILSSAC[34].

\section{Effect of $p H$}

The $\mathrm{pH}$ of the solution has a significant impact on the uptake of fluoride ions, since it determines the surface charge of the adsorbent, the degree of ionization and speciation of the adsorbate. In order to establish the effect of $\mathrm{pH}$ on the adsorption of fluoride ion, the batch equilibrium studies at different $\mathrm{pH}$ values were carried out in the $\mathrm{pH}$ range of 2-9 (Figure 2). At higher $\mathrm{pH}$ values the fluoride removal by the sorbents was found to decrease. The $\mathrm{pH}$ of the solution was adjusted by using $0.1 \mathrm{M}$ sodium hydroxide or hydrochloric acid. At $\mathrm{pH} 3$, the maximum amount of fluoride uptake was observed to be $3.25 \mathrm{mg} / \mathrm{gm}$ respectively. It is due to the availability of more $\mathrm{H}^{+}$ions in the surface of the adsorbent leading to greater adsorption of the fluoride. Hence, fluoride adsorption increases at low $\mathrm{pH}$ levels as more of the surface sites are positively charged. The adsorption of fluoride onto the surface of the material is may be due to the development of positively charged surface sites. 


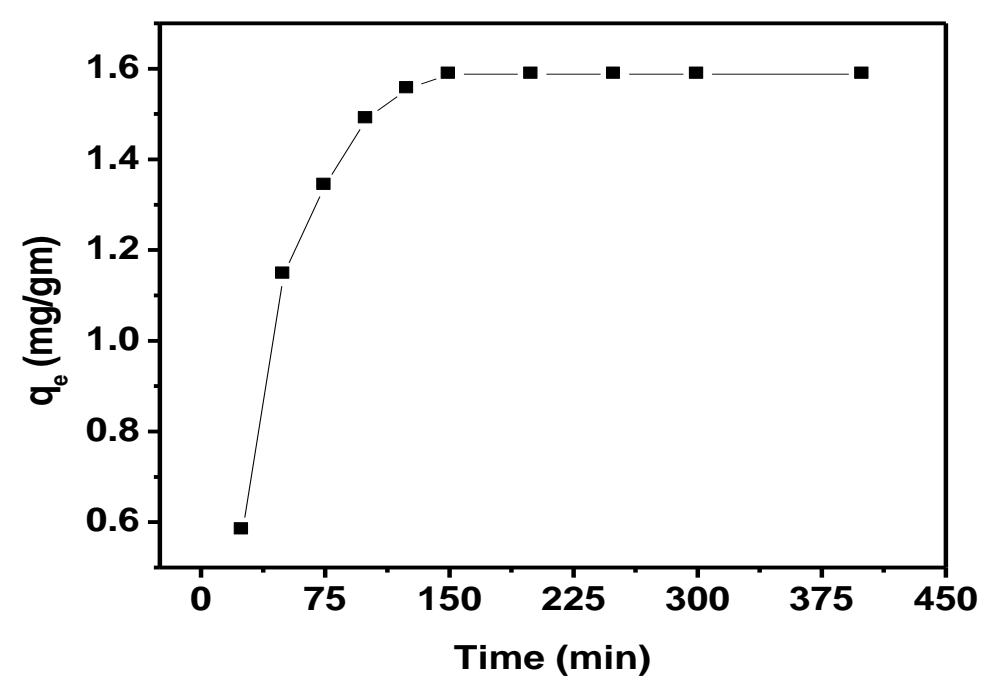

Figure 1: Effect of contact time on fluoride adsorption by ZILSSAC

\section{Effect of Adsorbent Dose}

One of the parameters that strongly affect the adsorption capacity is the concentration of the adsorbents. The effect of adsorbent dosage on the removal of fluoride from drinking water was studied at ambient $\mathrm{pH}$ and fluoride concentration of $10 \mathrm{mg} / \mathrm{l}$ for $150 \mathrm{~min}$. The adsorption loading is calculated based on equation 1.

Figure 3 indicates that, increasing adsorbent dosage increases fluoride uptake, indicating that for a fluoride removal an optimum ZILSSAC dosage of $2.0 \mathrm{~g} / \mathrm{L}$ was required. The result indicates that the fluoride removal efficiency increases up to this optimum dosage beyond which fluoride uptake has no significant change with ZILSSAC dosage. With the increase in the adsorbent dosage provides greater surface area and hence increases the adsorption. However, by increasing the adsorbent dosage beyond the optimum dosage, there may be a slight improvement in fluoride removal efficiency but the adsorption capacity decreases.

\section{Adsorption isotherms}

The sorption isotherm expresses the specific relation between the concentration of adsorbate and its degree to accumulation onto adsorbent surface at constant temperature ${ }^{44}$. The fluoride adsorption capacity of ZILSSAC was evaluated using two different isotherms namely Langmuir (Figure 4) and Freundlich (Figure 5) isotherms. The maximum adsorption capacity of the ZILSSAC was investigated at various concentrations from $5 \mathrm{ppm}$ to $50 \mathrm{ppm}$ of fluoride ion. The plot $\mathrm{C}_{\mathrm{e}} / \mathrm{qe}$ verses $\mathrm{C}_{\mathrm{e}}$ and plot of $\log \mathrm{C}_{\mathrm{e}}$ versus $\log \mathrm{q}_{\mathrm{e}}$ are shown in Figure 4 and Figure 5. 
J. Nepal Chem. Soc., vol. 30, 2012

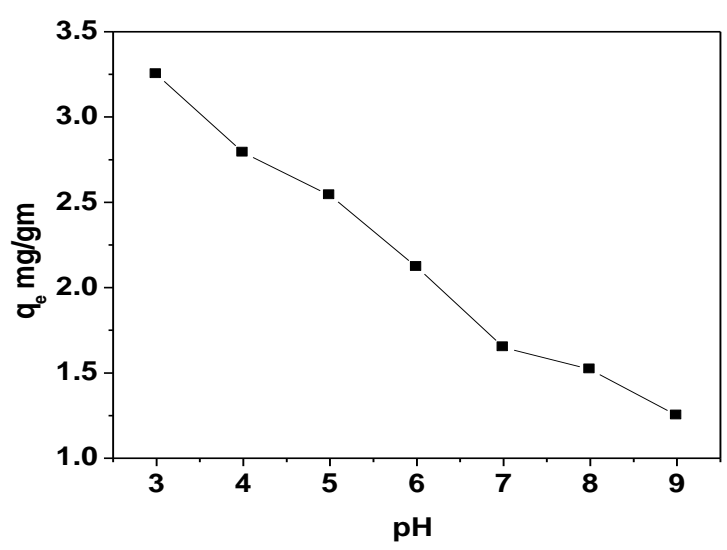

Fig.2: Effect of $p H$ on fluoride adsorption fluoride onto ZILSSAC

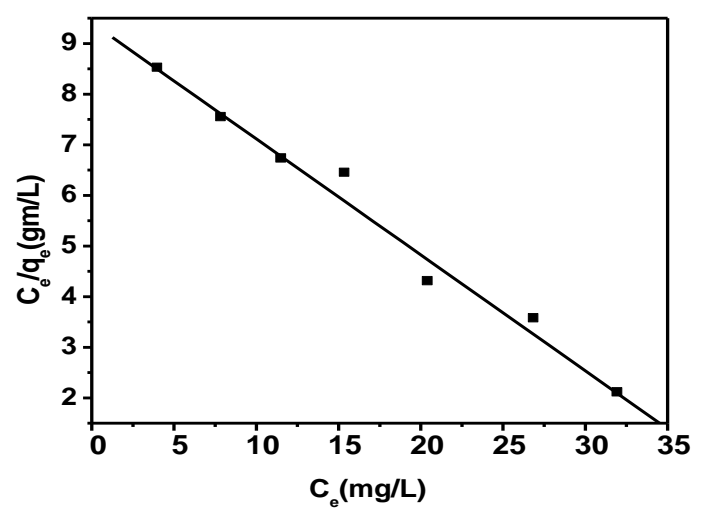

Fig.4 Plot of the Langmuir isotherm for fluoride fluoride adsorption on ZILSSAC. $\left(R^{2}=0.9768\right)$

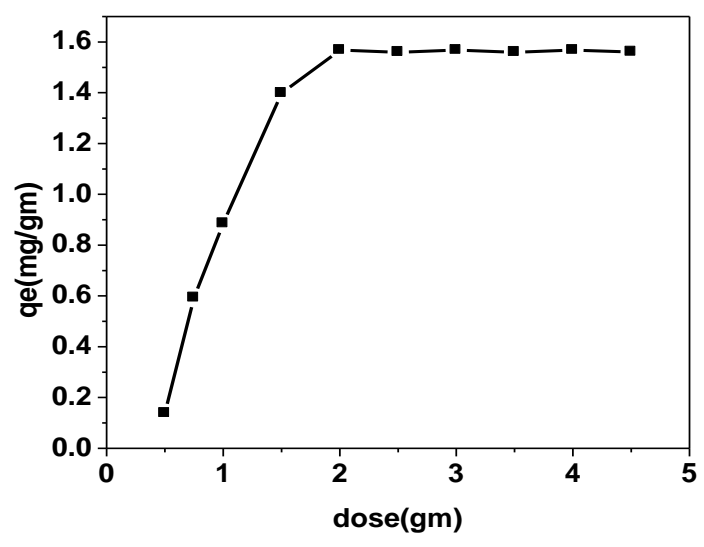

Fig.3: Effect of adsorbent dose on adsorption onto ZILSSAC

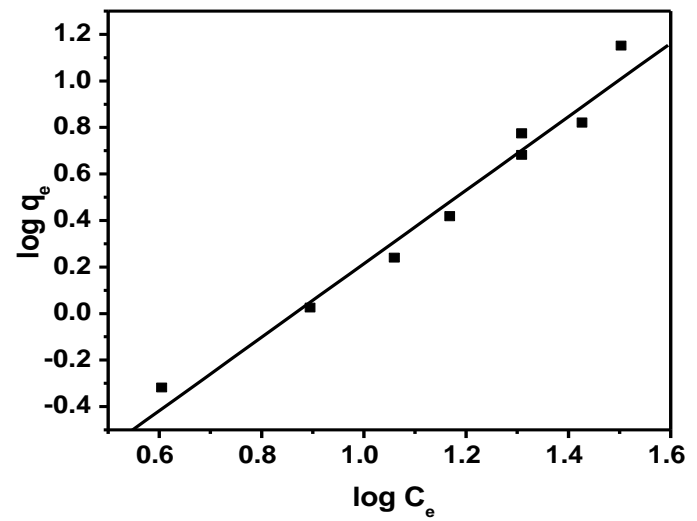

Fig.5 Plot of the Freundlich isotherm for sorption on ZILSSAC $\left(R^{2}=0.8828\right)$

\section{Langmuir Isotherm}

The linearized Langmuir adsorption isotherm, is expressed as

$$
\frac{C e}{q e}=\frac{1}{q \max } C e+\frac{1}{b} q \max
$$

Where $\mathrm{q}_{\mathrm{e}}$ is the amount adsorbed at equilibrium $(\mathrm{mg} / \mathrm{g}) ; \mathrm{C}_{\mathrm{e}}$ is the equilibrium concentration of fluoride ions in solution $(\mathrm{mg} / \mathrm{l})$.

\section{Freundlich Isotherm}

The linearized form of Freundlich equation is

$$
\log \mathrm{q}_{\mathrm{e}}=\log k_{f}+\frac{1}{n} \log \mathrm{Ce}
$$


Where, $K_{\mathrm{f}}$ and $1 / n$ are Freundlich isotherm constants, indicating the adsorption capacity and adsorption intensity, respectively.

The adsorption curves for ZILSSAC were applied to both Langmuir and Friendlich isotherms. The adsorption by adsorbent (ZILSSAC) was better fitted to Langmuir's isotherm which confirms monolayer adsorption. Hence the Langmuir's isotherm is applicable for adsorption of fluoride by ZILSSAC.

\section{Conclusion}

In this study, the possibility of utilization of Zirconium Ion Impregnated Lapsi Seed Stone Activated Carbon (ZIGNSC) as adsorbent for removal of fluoride from water was studied. Fluoride adsorption capacity is higher in acidic $\mathrm{pH}$. It decreases with increasing $\mathrm{pH}$ of the solution. The rate of removal (adsorption) of ZILSSAC is also influenced by $\mathrm{pH}$. Minimum contact time for maximum adsorption of fluoride was found to be $150 \mathrm{~min}$. The adsorption of fluoride onto Zirconyl Impregnated Carbon follows Langmuir isotherm i.e. Maximum adsorption corresponding to a saturated monomolecular layer of solute molecules on the adsorbent surface. From the experiment it is concluded that activated carbon prepared from Lapsi seed is an efficient, low-cost alternative to commercial activated carbon for defluoridation of water. This is a strong indication for its great potential application in fluoride removal from water as ZILSSAC provides a cost-effective working solution to the defluoridation problem in the developing countries.

\section{References}

1. M Amini, K Mueller, K.C Abbaspour, T. Rosenberg, M Afyuni, K.N Møller., M.Sarr, and C.A Johnson, Statistical modeling of global geogenic fluoride contamination in groundwaters, Environ. Sci. Technol., 2008, 42 3662-3668.

2. WHO, Guidelines for Drinking-Water Quality [Electronic Resource]: Incorporating First Addendum, (Ed.), 2006, 375-377.

3. S.J Gaciri., T.C Davies., The occurrence and geochemistry of fluoride in some natural waters of Kenya, J. Hydrol., 1993, 143, 395-412.

4. M Edmunds and P Smedley., Fluoride in natural waters. In Essentials of Medical Geology, Impacts of Natural Environment on Public Health, Elsevier Academic Press, 2005.

5. E.J Reardon., and Y Wang., Activation and regeneration of a soil sorbent for defluoridation of drinking water, Appl. Geochem., 2001, 16, 531-539.

6. F Shen., X Chen., P.Gao, G.Chen, Electrochemical removal of fluoride ions from industrial wastewater, Chem. Eng. Sci., 2003, 58, 987-993.

7. G. de la Puente, J.J. Pi., J.A. Menendez, and P Grange, Thermal stability of oxygenated functions in activated carbons, J. Anal. Appl. Pyrolysis., 1997, 43, 125-138.

8. S.Ayoob, and A.K .Gupta, Fluoride in drinking water: a review on the status and 12 stress effects, Crit. Rev. Environ. Sci. Technol., 2006, 36, 433-487.

9. M.Arora and R.C.Maheshwari, Investigations on the Batch Performance of Fluoride Adsorption by Coconut Shell Carbon Asian Journal of Water, Environment and Pollution, Vol. 4, No. 2, 119-122.

10. R.B Sah, and M. P Shrestha, Toxic containments in ground water of Terai plain of Kailali district, far western Nepal, Journal of SAN, 2006-2007, 6, 45-54 
11. P Shrestha., B Tuladhar, B.Dangol, and R.R Shrestha., "Partnership for Safe Water" initiative for the promotion of Household Water Treatment (HWT) options in Nepal, Twelfth Sustainable Development Conference (SDC), 2009.

12. S.Meenakshi, N.Viswanathan, Identification of selective ion-exchange resin for fluoride sorption, J. Colloid Interface Sci., 2007, 308, 438-450.

13. M.G.A. Sujana., R.S. Thakur., S.N. Das, S.B. Rao., Defluorination of waste waters, Asian J. Chem., 1997, 4, 561-570.

14. F. Durmaz, H. Kara, Y. Cengeloglu, M. Ersoz, Fluoride removal by Donnan dialysis with anion exchange membranes, Desalination, 2005, 177, 51-57.

15. M. Zeni, R. Riveros, K Melo., R Primieri., i S. Lorenzin, Study on fluoride reduction in artesian well water from electrodialysis process, Desalination, 2005, 185, 241-244K.

16. S. Sourirajan, T. Matsurra, Studies on reverse osmosis for water pollution control, Water Res., 1972, 6, 1073-1086.

17. R. Simons, Trace element removal from ash dam waters by nanofiltration and diffusion dialysis, Desalination, 1993, 89, 325-341.

18. Y. Guo, K Wang., Z.Yu, Xu H., Adsorption of Cr (IV) on micro- and mesoporous rice husk-based activated carbon, Mater. Chem. Phys., 2002, 78, 132-137.

19. M.S. Onyango, H. Matsuda, Fluoride removal from water using adsorption technique, in: A. Tressaud (Ed.), Fluoride and Environment, Elsevier B.V., The Netherlands, 2006, 2, 1-48.

20. Y. Ku, H. M. Chiou, The adsorption of fluoride ion from aqueous solution by activated alumina. Water, Air, Soil Pollut., 2002, 133, 349-360.

21. A. Sivasamy; K. P. Singh,; D. Mohan; Maruthamuthu, M. Studies on defluoridation of water by coal-based sorbents. J. Chem.Technol. Biotechnol. 2001, 76 (7), 717-722.

22. A. V. Ra; P. D. Nemade; B. J. Alappat, Removal of fluorides from water using low cost adsorbents. Water Sci. Technol.: Water Suppl., 2002, 311-317.

23. Y. Ku; H. M. Chiou; W. Wang, The removal of fluoride ion from aqueous solution by a cation synthetic resin. Sep. Sci. Technol, 2002, 37 (1), 89-103.

24. X Fan, D. J. Parker, M. D. Smith, Adsorption kinetics of fluoride on low cost materials. Water Res., 2003, 37, 4929-4937.

25. Y. Cengeloglu, E. Kir and M. Ersoz Removal of fluoride from aqueous solution by using red mud. Sep. Purif. Technol, 2002,

26. R. Sathish, N. Raju, G. Raju, G. Rao; Anil K Kumar., C. Janardhana, Equilibrium and Kinetic Studies for Fluoride Adsorption from Water on Zirconium Impregnated Coconut Shell Carbon, separation Science and Technology, 2007 March, 42, 769 - 788.

27. W.T. Tsai, C.Y. Chang, S.Y. Wang, C.F. Chang, S.F. Chien, H.F. Sun Cleaner production of carbon adsorbents by utilizing agricultural waste corn cob Resources, Conservation and Recycling, 2001, 32, 43-53.

28. F. Luo, K. Inoue, The removal of fluoride ion by using metal (III)—loaded Amberlite resins, Solv. Extr. Ion Exch., 2004, 22, 305.

29. H.C. Loh, S.M. Ng, and M. Ahmad, Accurate Zirconium Detection at Visible Wavelength Using Artificial Neural Network Anal Lett., 2005, 38, 1305-1316.

30. S. Perbiemi, M. Ahlgren, Optimized arsenic, selenium and mercury determinations in aqueous solutions by energy dispersive $\mathrm{x}$-ray fluorescence after pre-concentration onto zirconium-loaded activated charcoal, Analytica Chimica Acta, 1995, 302, 80-95.

31. G.N. Nageswara, R. S. Sathish, P. Sunil Kumar, V. Anil Kumar, M.V. Madhav, Study on defluoridation of drinking water using Zirconium impregnated activated charcoals, Indian Journal of technology, 2007, 14, 350-354. 
32. G. N. Rao, R. S. Sathish, V. S. laxman, study on defluoridation of drinking water by impregnation of metal ions in activated carbon, Indian Journal of technology, 2006, 13, 414-416.

33. R. S. Sathish, S. Sairam, V.G. Raja, G.N. Nageswara, Defluridation of water using Zirconium Impregnated Coconut fibre carbon, Separation of Science and Technology, 2008, 43, 3676-3694.

34. G. Alagumuthu, M. Rajan, Kinetic and equilibrium studies of fluoride removal by Zirconium (IV)Impregnated groundnut shell carbon, Hem. ind., 2010, 64 (4), 295-304.

35. X. Pinliao and b. shi, Adsorption of Fluoride on Zirconium (IV)-Impregnated Collagen Fiber, Environ. Sci. Technol., 2005, 39, 4628-4632.

36. Z. Al. Qodah and R. Shawabkah,Production and characteristics of granular activated carbon from activated sludge, Brazilian Journal of Chemical Engineering, 2009, 26(1), 127 - 136.

37. K. C. Paude, K. Pieber, R. Klumpp and M. Laimer, Evaluation of Lapsi tree (Choerospondias Axillaris, Roxb.) for fruit production in Nepal, 2003, www.boku.ac.at/diebodenkultur/volltexte/band-54/paudel.pdf

38. R.Rajbhandari, L.K.Shrestha and R.R.Pradhananga, Nanoporous Activated Carbon Derived from Lapsi (Choerospondias axillaris) Seed Stone for the Removal of Arsenic from water, Journal of Nanoscience and Nanotechnology( in Press)

39. R.M. Shrestha A.P. Yadav,B.P.Pokharel and R.R. Pradhananga, Preparation and Characterization of Activated Carbon from Lapsi (Choerospondias axillaris) Seed Stone by Chemical Activation with Phosphoric acid, ISCA- Research Journal of Chemical Sciences (in press)

40. American Public Health Association, Standard Methods for Examination of water and waste water Washington DC, (2005)

41. American Society for Testing and Materials. 2006 Annual Book of Standards, 2006

42. ASTM D4607 - 94(2011) Standard Test Method for Determination of Iodine Number of Activated Carbon

43. S.L. Goertzen, Kim D. The'riault, Alicia M. Oickle Anthony C. Tarasuk Heather A. Andreas Standardization of the Boehm titration. Part $\mathrm{I} . \mathrm{CO}_{2}$ expulsion and endpoint determination, Carbon 48(2010) 1252-1261.

44. K.Li, Z.Zheng, Ye, Li, Characterization and lead adsorption properties of activated carbons prepared from cotton stalk by one step $\mathrm{H}_{3} \mathrm{PO}_{4}$ activation, Journal of Hazardous Materials 181(2010) 440-447 